\title{
A quantitative study of some agronomic characters in Sulla (Hedysarum coronarium L.)
}

\author{
Imene Louati-Namouchi*, Mehdi Louati, Ali Chriki \\ Laboratoire de Génétique, Faculté des Sciences de Bizerte, 7021 Zarzouna, Tunisia
}

(Received 24 August 1999; accepted 22 December 1999)

\begin{abstract}
Eleven populations of Hedysarum coronarium L. collected from North Africa and Southern Italy were analyzed using both univariate and multivariate analyses on a data set for 25 quantitative traits. Broad sense heritabilities were estimated and ranged from 0.072 to 0.703 . Seven principal components were found to explain $81.5 \%$ of the total variation. On the basis of these 7 principal components, populations were clustered at a similarity level estimated by euclidian distances. Three clusters were identified. Genetic divergence between these clusters was quantitatively measured by using Mahalanobis $\mathrm{D}^{2}$ distances.
\end{abstract}

cluster analysis / Hedysarum coronarium / heritability / morphological variability / multivariate analysis

Résumé - Étude quantitative de quelques caractères agronomiques chez le Sulla (Hedysarum coronarium $\mathbf{L}$.). Vingt cinq caractères morphologiques ont été mesurés chez 11 populations de Hedysarum coronarium collectées de l'Afrique du Nord et de l'Italie du Sud. Les données obtenues ont été soumises à une analyse univariée et une analyse multivariée. L'héritabilité au sens large a été estimée ; elle varie entre 0,072 et 0,703. L'ACP révèle que 7 composantes principales absorbent $81.5 \%$ de la variance totale. L'application de la méthode de classification hiérarchique sur la matrice des distances euclidiennes a permis de répartir les populations en 3 groupes. L'utilisation de la distance de Mahalanobis $\mathrm{D}^{2}$ a permis d'estimer la divergence génétique entre ces groupes.

analyse multivariée / classification hiérarchique / Hedysarum coronarium / héritabilité / variabilité morphologique

Communicated by Mervyn Humphreys (Aberystwyth, UK)

* Correspondence and reprints

m.louati@excite.com 


\section{Introduction}

Hedysarum coronarium $\mathrm{L} .(2 \mathrm{n}=2 \mathrm{x}=16)$, often called "Sulla", has value as a forage species and is of considerable agronomic interest. It is characterized by considerable morphological variability $[9$, 21], and in Tunisia its distribution is limited to the north of the country. Native plants of this annual species are generally prostrate, with a variable number of prostrate branches having short internodes and small leaflets. Plants with an erect growth habit are rarely found in natural populations, although improved varieties originating from Italy have an erect growth habit such as the "Grimaldi" variety recently introduced into Tunisia. However, this cultivar has a woody stem and is not favored by livestock. Also, greenhouse observations indicate that this variety is sensitive to Podosphaera leucotricha, the causal agent of Oïdium. Therefore, it would be useful to breed improved varieties with the good agronomic characteristics of "Grimaldi" (such as an erect growth habit, long leaves, large leaflets and good biomass) combined with those of wild populations of Sulla (such as less woody stems and resistance to Oïdium).

Assessment of morphological variability is an important stage in breeding programs. Seed collec- tions of populations from different geographical origins may contain useful genetic variation. Several studies on different plant species for a number of morphological characters indicate significant variability between populations $[12,13$, $18,22]$, and the application of hierarchical cluster analysis allows estimation of genetic distances separating populations. Our objective was to study morphological variability in $H$. coronarium in terms of a broad range of traits. The heritability of each trait was estimated and a multivariate analysis was applied to classify the populations with the aim of identifying useful material for breeding programs.

\section{Materials and methods}

The seeds used in this study were collected from 8 wild populations and from 3 Italian cultivars of $H$. coronarium. The sites of origin are indicated in Figure 1.

About 60 seeds from each population were germinated in petri dishes on wet filter paper. They were manually scarified in order to increase their germination percentage. Seedlings were transplanted to pots, $20 \mathrm{~cm}$ in diameter, in the greenhouse of

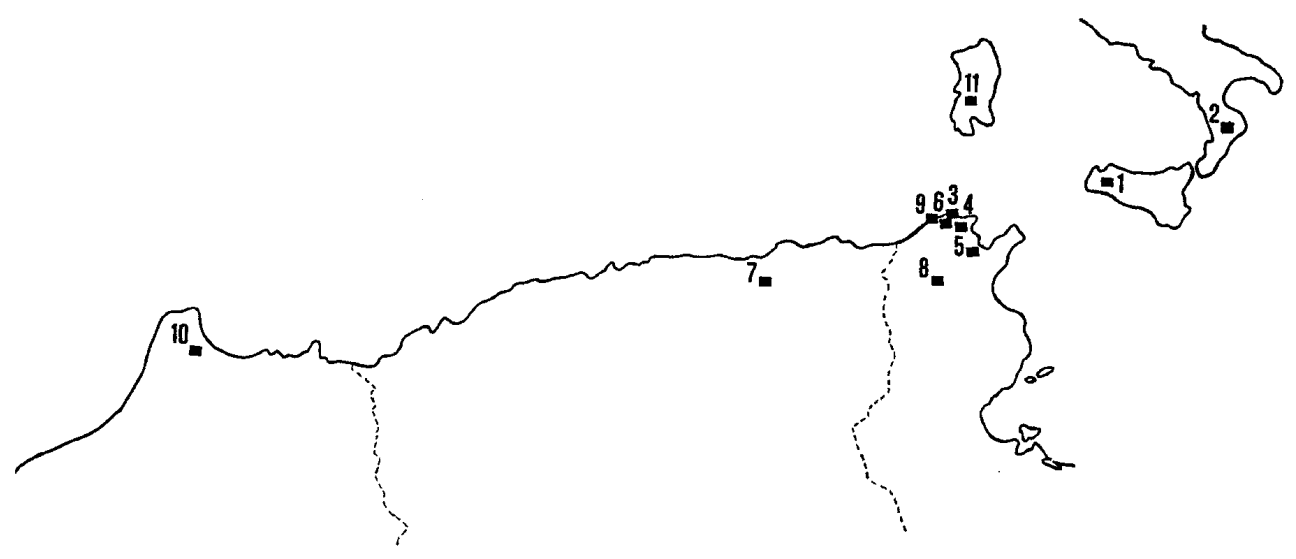

Figure 1. Collection sites of 11 studied Hedysarum coronarium populations: 1: Monteroni Sicily (Italy); 2: Vicigliano (Italy); 3 : Nadour (Tunisia); 4: El Alia (Tunisia); 5: Tunis (Tunisia); 6: Bougabrine (Tunisia); 7: ALO56 (Algeria); 8: Maktar (Tunisia); 9 : Amaïria (Tunisia); 10: Ma 008 (Morocco); 11: Sa 004 Sardinia (Italy). 
the Faculté des Sciences de Bizerte, Tunisia. They were arranged in 3 randomized complete blocks with 7 plants per population and per block. Twenty-five morphological characters were recorded. They were divided into 2 categories: vegetative characters and reproductive characters (Tab. I). The data was analyzed by 2-way analysis of variance (ANOVA) with fixed populations and random blocks [6].

Phenotypic variance (p) was divided into environmental (e) and genetic (g) components, since $\mathrm{p}=\mathrm{g}+\mathrm{e}$. These components were calculated as in [12], with 10 degrees of freedom (d.f.) for between populations, 2 d.f. for between blocks and 20 d.f. for populations $\times$ blocks.

Genetic variance was estimated as:

$$
\mathrm{g}=(\text { MSpop }- \text { MSpop } \times \text { block }) / n b ;
$$

where: $\mathrm{MSpop}=$ population mean square;

MSpop $\times$ block $=$ interaction mean square;

$$
\begin{gathered}
n=\text { number of repetitions }(=7) ; \\
b=\text { number of blocks }(=3) .
\end{gathered}
$$

Environmental variance was estimated as:

$$
\mathrm{e}=\text { MSpop } \times \text { block }
$$

Table I. Quantitative traits measured in $H$. coronarium.

\begin{tabular}{lll}
\hline Character & Abbreviation & Signification \\
\hline \multicolumn{2}{l}{ Vegetative characters } & \\
C1 & FPL & First leaf petiole length \\
C2 & FTL & Total length of the first leaf \\
C3 & FLL & First leaf limb length \\
C4 & FLW & First leaf limb width \\
C5 & NUF & Number of unifoliate leaves \\
C6 & NPL & Total number of prostrate axis \\
C7 & LPA & Length of the axis holding the first inflorescence \\
C8 & NSPA & Number of ramifications of axis in C7 \\
C9 & FPA & Number of leaves of axis in C7 \\
C10 & LF & Total length of the leaf axilling the first inflorescence \\
C11 & NF & Number of leaflets of C10 \\
C12 & FL & Terminal leaflet length of C10 \\
C13 & FW & Terminal leaftet width of C10 \\
C14 & LOF & Length of the erect axis \\
C15 & PPL & Length of the longest prostrate axis \\
C16 & NEN & Number of internodes of the longest prostrate axis \\
C17 & TSL & Length of all aerial axes \\
& & \\
Reproductive characters & FD & Flowering date \\
C18 & NIF & Number of inflorescences \\
C19 & NMF & Flowers / inflorescence \\
C20 & D1 & Total length of the inflorescence (cm) \\
C21 & D2 & Insertion level of the first flower on the inflorescence (cm) \\
C22 & EL & \\
C23 & CL & Standard petal length (cm) \\
C24 & Keel petal length (cm) \\
C25 & & Keel petal width (cm) \\
& &
\end{tabular}

For the variables $\mathrm{C}_{20}$ to $\mathrm{C}_{25}$ which are associated with reproductive characters, each value represents a mean of 5 measures on 5 different flowers (or inflorescences) per plant. 
The determination of $\mathrm{g}$ and e allowed betweenpopulation heritabilities $\left(\mathrm{H}^{2}\right)$ to be calculated as $[12,13]$ :

$$
\mathrm{H}^{2}=\frac{\mathrm{g}}{\mathrm{g}+\mathrm{e}} .
$$

Principal components analysis (PCA) was carried out after standardization of the original data to zero means and unit variance. This analysis defined principal components which were synthetic and independent variables representing linear combinations of the original correlated measured variables. Euclidian distances were established from the population means of PCA scores, and a cluster analysis (average linkage method) was performed.

\section{Results}

The results of the 2-way analysis of variance for each measured trait are shown in Table II. Of the 25 traits measured, 4 failed to show significant differences between-populations and were omitted from further analyses. These included the total length of the first leaf (FTL), the dimensions of the first leaf (FLL and FLW), and the number of ramifications of the axis holding the first inflorescence (NSPA).

For the 21 characters which demonstrated significant population differences, genetic $(\mathrm{g})$ and environmental (e) components of between-population variation were calculated and are given in Table III together with estimates of between-population heritabilities $\left(\mathrm{H}^{2}\right)$. The character "length of the erect axis" (LOF) showed the greatest heritability (0.703). This character was successfully used in selecting the variety Grimaldi (which has a welldeveloped erect axis). This variety is extensively commercialized and intensively cultivated in Tunisia. The other vegetative characters gave heritabilities which varied between 0.072 (for FPL) and 0.602 (for LF). For the reproductive characters $\left(\mathrm{H}^{2}=0.144-0.607\right)$, the heritability was distinctly larger for traits associated with floral part dimensions (CL, CW and EL) and inflorescence dimensions (D1 and D2). Higher values of $\mathrm{H}^{2}$ correspond
Table II. Variance components for measured traits in $H$. coronarium.

\begin{tabular}{lccccr}
\hline Character & MSp & MSb & MSpxb & MSe & \multicolumn{1}{c}{ Fp } \\
\hline FD & 14.884 & 2.0554 & 1.4046 & 0.2521 & $10.53^{\mathrm{a}}$ \\
CL & 13.9444 & 0.2096 & 0.6408 & 0.3905 & $21.76^{\mathrm{a}}$ \\
CW & 12.8295 & 0.2268 & 0.6066 & 0.4501 & $21.15^{\mathrm{a}}$ \\
NMF & 12.1957 & 9.5627 & 1.3552 & 0.3122 & $9.00^{\mathrm{a}}$ \\
LOF & 16.35 & 0.1233 & 0.3226 & 0.3020 & $50.69^{\mathrm{a}}$ \\
NPL & 7.0767 & 4.6896 & 0.7647 & 0.6796 & $9.25^{\mathrm{a}}$ \\
PPL & 9.8184 & 1.3974 & 0.9133 & 0.5594 & $10.75^{\mathrm{a}}$ \\
NEN & 9.1721 & 5.286 & 0.7401 & 0.5702 & $12.39^{\mathrm{a}}$ \\
LPA & 11.0592 & 10.3138 & 0.5449 & 0.5363 & $20.30^{\mathrm{a}}$ \\
NSPA & 0.9017 & 1.0935 & 1.0448 & 0.5080 & $0.86^{*}$ \\
FPA & 9.8416 & 21.6 & 0.8366 & 0.4964 & $11.76^{\mathrm{a}}$ \\
LF & 13.7467 & 1.0398 & 0.4200 & 0.4144 & $32.73^{\mathrm{a}}$ \\
NF & 8.7784 & 0.4287 & 0.6220 & 0.6165 & $14.11^{\mathrm{a}}$ \\
FL & 7.8532 & 0.5548 & 0.6156 & 0.5341 & $12.76^{\mathrm{a}}$ \\
FW & 7.1025 & 0.3944 & 0.8016 & 0.6946 & $8.86^{\mathrm{a}}$ \\
FPL & 5.2399 & 0.0388 & 2.0217 & 0.6924 & $2.59^{\mathrm{b}}$ \\
NUF & 7.9982 & 5.3629 & 1.4131 & 0.5608 & $5.66^{\mathrm{a}}$ \\
EL & 14.4510 & 0.1463 & 0.5888 & 0.3896 & $24.54^{\mathrm{a}}$ \\
D1 & 15.6009 & 0.1942 & 0.4665 & 0.4460 & $33.44^{\mathrm{a}}$ \\
D2 & 16.3004 & 1.5675 & 0.5559 & 0.3881 & $29.32^{\mathrm{a}}$ \\
NIF & 6.3649 & 0.1930 & 1.4001 & 0.6819 & $4.55^{\mathrm{a}}$ \\
TSL & 4.9347 & 4.5704 & 1.4508 & 0.6582 & $3.40^{\mathrm{b}}$ \\
FLL & 4.9014 & 0.1395 & 2.4070 & 0.6382 & $2.04^{*}$ \\
FLW & 2.8651 & 4.6357 & 2.8069 & 0.6232 & $1.02^{*}$ \\
FTL & 6.5460 & 0.0969 & 2.8141 & 0.6701 & $2.33^{*}$ \\
\hline
\end{tabular}

MSp: mean square population; MSb: mean square block; MSpxb: mean square interaction; MSe: residual mean square; Fp: $F$ test of population effect.

${ }^{a}$ Population effect significant at $\mathrm{P}<1 \%$; ${ }^{\mathrm{b}}$ population effect significant at 5\%; * population effect not significant at 5\%.

to characters which show large population differences as it is shown by the strong positive correlation between heritability $\mathrm{H}^{2}$ and the Fp ratio $(\mathrm{r}=$ 0.942).

Standardization of phenotypic raw data is necessary due to the large differences in the scale of measurement $[12,13,23]$. The data matrix obtained was submitted to various multivariate analyses. PCA was carried out using the correlation matrix for all the 21 characters showing a significant genotype effect, and a hierarchical cluster analysis of populations was performed. 
Table III. Genetic (g) and environmental (e) components of variance and between population heritabilities $\left(\mathrm{H}^{2}\right)$ for 21 traits.

\begin{tabular}{lccc}
\hline Character & $\mathrm{g}$ & $\mathrm{e}$ & $\mathrm{H}^{2}$ \\
\hline FD & 0.6418 & 1.4046 & 0.314 \\
CL & 0.6335 & 0.6408 & 0.497 \\
CW & 0.5820 & 0.6066 & 0.490 \\
NMF & 0.5162 & 1.3552 & 0.276 \\
LOF & 0.7632 & 0.3226 & 0.703 \\
NPL & 0.3006 & 0.7647 & 0.341 \\
PPL & 0.4240 & 0.9133 & 0.317 \\
NEN & 0.4015 & 0.7401 & 0.352 \\
LPA & 0.5007 & 0.5449 & 0.479 \\
FPA & 0.4288 & 0.8366 & 0.339 \\
LF & 0.6346 & 0.4200 & 0.602 \\
NF & 0.3884 & 0.6220 & 0.384 \\
FL & 0.3446 & 0.6156 & 0.359 \\
FW & 0.3000 & 0.8016 & 0.272 \\
FPL & 0.1575 & 2.0217 & 0.072 \\
NUF & 0.3135 & 1.4131 & 0.182 \\
EL & 0.6601 & 0.5888 & 0.529 \\
D1 & 0.7207 & 0.4665 & 0.607 \\
D2 & 0.7497 & 0.5559 & 0.574 \\
NIF & 0.2364 & 1.4001 & 0.144 \\
TSL & 0.1659 & 1.4508 & 0.103 \\
\hline
\end{tabular}

Table IV. Eigenvalue, percentage variance accounted for and cumulative variance for the first 7 principal components identified.

\begin{tabular}{lccc}
\hline Component & Eigenvalues & $\begin{array}{c}\text { Percentage } \\
\text { variance }\end{array}$ & $\begin{array}{c}\text { Cumulative } \\
\text { variance }\end{array}$ \\
\hline 1 & 6.9866 & 33.3 & 33.3 \\
2 & 3.7782 & 18.0 & 51.3 \\
3 & 1.5860 & 7.6 & 58.8 \\
4 & 1.5509 & 7.4 & 66.2 \\
5 & 1.3253 & 6.3 & 72.5 \\
6 & 1.0231 & 4.9 & 77.4 \\
7 & 0.8634 & 4.1 & 81.5 \\
\hline
\end{tabular}

Based on eigenvalues of the order of 0.8 as was suggested by [20], the PCA grouped the variables into 7 components (Tab. IV). These 7 principal components explained $81.5 \%$ of the total variance. The loadings are shown in Table V; correlation coefficients between the original data (standardized matrix) and the PCA scores were also calculated. Table V presents data which allows us to interpret each principal axis by its correlations with the original variables. If we consider the plane defined just by the first 2 principal components, which accounted for $51.3 \%$ of the total variation, 2 groups of characters can be distinguished (Fig. 2):

(i) The first group includes variables positively correlated to axis 1 . These are the dimensions of floral parts (CW, CL, EL) and of the inflorescence $\left(\mathrm{D}_{1}, \mathrm{D}_{2}\right)$, the mean number of inflorescences (NMF) and the length of the erect axis (LOF).

(ii) The second group of variables associated with axis 2 essentially represents the vegetative development of the plant. This axis is negatively correlated to characters NPL, PPL, NEN, TSL and also to the total number of inflorescences (NIF).

In order to improve the hierarchical cluster analysis of populations, we included just the 7 first principal components, accounting for $81.5 \%$ of the total variation. For this, we used the matrix of euclidian distances calculated from the population mean PCA scores. The clustering method applied was that of average linkage which is based on the regrouping of populations at similarity level estimated by euclidian distances. The dendrogram obtained is represented in Figure 3. It shows that at a distance of the order of 2.84 , the 11 populations are distributed into 3 groups:

Group 1 consists of the 3 Italian populations (Monteroni, Vicigliano and $\mathrm{Sa004}$ ) and 2 populations of different geographical origin: a Moroccan population (Morocco 008) and a Tunisian population (Nadour).

Group 2 includes only natural populations originating from Tunisia (El Alia, Bougabrine, Maktar and Tunis).

Group 3 associates the Algerian natural population (A1056) with the Grimaldi cultivar originating from the Tunisian population Amairia.

Mahalanobis distances representing the extent of genetic separation between the groups of populations are given in Table VI. This information may be used to determine which interpopulation crosses 


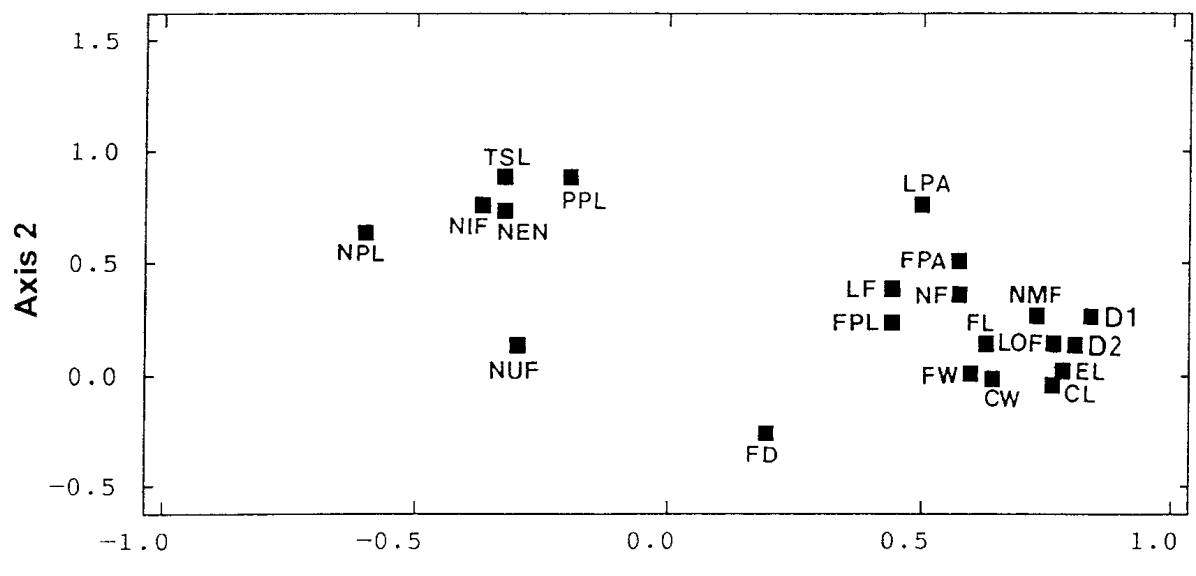

Axis 1

Figure 2. Scatter plot of variables for the first 2 principal components.

Table V. Loadings for the 7 principal components derived from phenotypic correlations between the measured traits.

\begin{tabular}{|c|c|c|c|c|c|c|c|}
\hline Character & Axis 1 & Axis 2 & Axis 3 & Axis 4 & Axis 5 & Axis 6 & Axis 7 \\
\hline FD & 0.188 & -0.265 & 0.420 & -0.623 & -0.355 & 0.085 & 0.069 \\
\hline CL & 0.772 & -0.031 & 0.120 & 0.369 & -0.328 & 0.068 & 0.093 \\
\hline CW & 0.649 & -0.085 & 0.100 & 0.528 & -0.367 & 0.134 & 0.014 \\
\hline NMF & 0.743 & 0.192 & -0.061 & -0.279 & 0.085 & 0.059 & -0.236 \\
\hline LOF & 0.779 & 0.092 & -0.338 & 0.037 & 0.259 & 0.002 & 0.201 \\
\hline NPL & -0.592 & 0.618 & -0.042 & 0.173 & 0.019 & 0.182 & 0.049 \\
\hline PPL & -0.200 & 0.779 & 0.322 & -0.069 & -0.254 & -0.150 & -0.213 \\
\hline NEN & -0.329 & 0.733 & 0.344 & 0.070 & -0.254 & -0.181 & -0.001 \\
\hline LPA & 0.495 & 0.666 & 0.102 & -0.353 & -0.046 & 0.087 & -0.003 \\
\hline FPA & 0.575 & 0.474 & -0.003 & -0.220 & -0.029 & 0.203 & 0.310 \\
\hline LF & 0.447 & 0.285 & 0.117 & 0.006 & 0.201 & -0.532 & 0.488 \\
\hline $\mathrm{NF}$ & 0.557 & 0.372 & -0.367 & -0.055 & -0.157 & -0.239 & 0.116 \\
\hline FL & 0.642 & 0.047 & 0.489 & 0.216 & 0.378 & -0.015 & -0.200 \\
\hline FW & 0.598 & -0.001 & 0.407 & 0.260 & 0.484 & -0.052 & -0.219 \\
\hline FPL & 0.428 & 0.164 & -0.451 & 0.060 & -0.036 & 0.397 & -0.077 \\
\hline NUF & -0.287 & 0.008 & 0.463 & -0.013 & 0.255 & 0.548 & 0.446 \\
\hline EL & 0.771 & -0.086 & 0.126 & 0.350 & -0.417 & 0.064 & 0.041 \\
\hline D1 & 0.791 & 0.078 & -0.063 & -0.241 & 0.162 & 0.033 & -0.090 \\
\hline D2 & 0.838 & 0.196 & -0.059 & -0.188 & 0.050 & 0.059 & -0.137 \\
\hline NIF & -0.373 & 0.696 & -0.196 & 0.343 & 0.182 & 0.003 & 0.086 \\
\hline TSL & -0.317 & 0.816 & -0.076 & 0.028 & 0.055 & 0.207 & -0.179 \\
\hline
\end{tabular}

are likely to give the most heterosis through genetic recombination [13]. The highest genetic divergence occurred between clusters 2 and $3\left(\mathrm{D}^{2}=\right.$ 25.3457).
In order to identify the characters which discriminate between the 3 groups of populations, the means and standard deviations of traits were calculated for each group separately. Comparisons of 
Table VI. Matrix of Mahalanobis squared distances between the 3 groups.

\begin{tabular}{lccc}
\hline Group & 1 & 2 & 3 \\
\hline 1 & 0.0000 & 7.0293 & 20.7824 \\
2 & & 0.0000 & 25.3457 \\
3 & & & 0.0000 \\
\hline
\end{tabular}

trait means between groups using an F test (Tab. VII) show that the means differ significantly for all the characters, at least for 2 of the 3 groups. Group 1 possesses the highest means for 5 traits: date of flowering, length of the longest prostrate axis, number of internodes, length of the axis holding the first inflorescence and total length of all aerial axes. Group 2 possesses the highest means for 3 characters: number of unifoliate leaves, number of prostrate axes and the total number of inflorescences. Group 3 possesses the highest means for the 13 other characters which are associated with flower and inflorescence dimensions, length of the erect axis and leaf dimensions.

\section{Discussion}

Although the evaluation of heritability by the method of Humphreys [12, 13] is approximate, it provides initial values for decisions on programs of varietal selection $[11,14]$. Our study showed that the character "length of the erect axis" (LOF) gave the highest between-population heritability. Estimates of heritability showed considerable differences among the other vegetative traits $\left(\mathrm{H}^{2}=\right.$ 0.072-0.602). Reproductive characters maintained by natural selection allows this allogamous species [5] to be adapted to entomophilic pollination. Flowers of large size and bright in color (in the red spectrum) attract pollinators, notably bees [10]. High heritabilities for the flower parts indicate a potential for selection on flower size. Large flowers are considered to be an important component of reproductive success [7]. Heritabilities found in our study are in good agreement with those found for other species [19, 25]. However in our study, we estimated broad sense heritabilities which represent a summary evaluation of the total level of genetic variation. It could be biased upwards by a non-additive genetic variation $[15,16]$, and is considered to represent the upper limits for narrowsense heritability [8, 24].

Information obtained through PCA may assist plant breeders to identify a limited number of highly differentiated populations for use in programs of crossing and selection [22]. It can be seen from the clustering pattern shown in Figure 3 that the grouping of populations does not strictly represent the geographic origin, since very distant populations such as the grouping of the Tunisian population Nadour and the Moroccan population Morocco 008

\section{Distance}

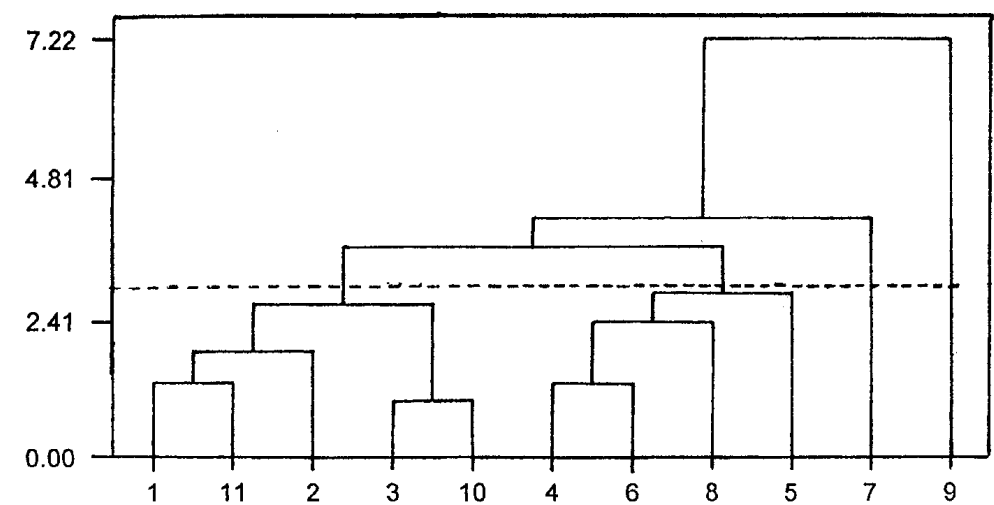

Figure 3. Hierarchical classification of the 11 populations based on euclidian distances. 
Table VII. Comparison of means for each group by the Fisher test.

\begin{tabular}{|c|c|c|c|c|c|c|c|}
\hline \multirow[t]{2}{*}{ Variable } & \multicolumn{2}{|c|}{ Group $1(\mathrm{n}=105)$} & \multicolumn{2}{|c|}{ Group $2(n=84)$} & \multicolumn{2}{|c|}{ Group $3(n=42)$} & \multirow[b]{2}{*}{ SDc } \\
\hline & Mean & SD & Mean & SD & Mean & SD & \\
\hline DF & 152.42 (a) & 19.17 & 149.93 (a) & 9.36 & 141.69 (b) & 17.68 & 15.99 \\
\hline CL & 1.4334 (a) & 0.0777 & 1.3134 (b) & 0.1232 & $1.5495(\mathrm{c})$ & 0.0846 & 0.0978 \\
\hline $\mathrm{CW}$ & 0.67572 (a) & 0.05989 & $0.63285(\mathrm{~b})$ & 0.05515 & 0.76964 (c) & 0.04144 & 0.05525 \\
\hline NMF & 30.624 (a) & 7.156 & $23.845(\mathrm{~b})$ & 5.112 & 33.524 (a) & 13.772 & 8.184 \\
\hline LOF & 18.34 (a) & 22.39 & $2.83(\mathrm{~b})$ & 5.80 & $64.20(\mathrm{c})$ & 41.06 & 23.33 \\
\hline NPL & 5.638 (a) & 2.122 & $6.583(b)$ & 2.396 & 3.595 (c) & 2.285 & 2.254 \\
\hline PPL & 90.74 (a) & 22.97 & $68.01(b)$ & 16.63 & $45.79(\mathrm{c})$ & 29.98 & 22.43 \\
\hline NEN & 13.743 (a) & 3.217 & $11.274(b)$ & 2.175 & 8.167 (c) & 4.818 & 3.258 \\
\hline LPA & 73.36 (a) & 16.84 & $54.35(\mathrm{~b})$ & 16.16 & $63.25(\mathrm{c})$ & 28.56 & 19.27 \\
\hline FPA & 10.924 (a) & 1.965 & $9.179(\mathrm{~b})$ & 2.340 & $12.310(\mathrm{c})$ & 4.199 & 2.631 \\
\hline LF & $10.630(\mathrm{a})$ & 2.163 & $6.940(\mathrm{~b})$ & 1.507 & $12.657(\mathrm{c})$ & 5.831 & 3.012 \\
\hline NF & 8.905 (a) & 1.355 & $7.250(\mathrm{~b})$ & 1.307 & $9.262(\mathrm{a})$ & 1.822 & 1.434 \\
\hline FL & 3.239 (a) & 0.5141 & $2.8202(b)$ & 0.5222 & 3.5857 (c) & 0.6547 & 0.5449 \\
\hline FW & 2.1524 (a) & 0.3153 & $1.9143(\mathrm{~b})$ & 0.3687 & $2.4357(\mathrm{c})$ & 0.3925 & 0.3501 \\
\hline FPL & 3.0867 (a) & 0.8846 & 2.8464 (a) & 0.7911 & 3.9167 (b) & 1.457 & 0.9831 \\
\hline NUF & 3.695 (a) & 0.748 & $4.750(\mathrm{~b})$ & 1.472 & 3.548 (a) & 0.670 & 1.06 \\
\hline EL & 1.6031 (a) & 0.1342 & $1.4610(\mathrm{~b})$ & 0.152 & 1.7965 (c) & 0.1152 & 0.1379 \\
\hline D1 & 9.467 (a) & 2.012 & $7.148(\mathrm{~b})$ & 1.614 & $10.668(\mathrm{c})$ & 4.881 & 2.661 \\
\hline D2 & $5.082(a)$ & 1.676 & $3.123(b)$ & 0.838 & $6.284(\mathrm{c})$ & 3.371 & 1.892 \\
\hline NIF & 31.50 (a) & 16.94 & 31.86 (a) & 14.79 & $24.40(\mathrm{~b})$ & 14.36 & 15.73 \\
\hline TSL & 451.0 (a) & 224.2 & 388.2 (b) & 210.0 & $241.4(\mathrm{c})$ & 137.1 & 205.8 \\
\hline
\end{tabular}

SD: Standard deviation; $\mathrm{SD}_{\mathrm{c}}$ : cumulated standard deviation.

$a, b, c:$ The means followed by the same letter are not significantly different at the $5 \%$ probability level.

were found to be associating with Italian populations. In other studies, it was also found that populations clustered in different groups irrespective of their countries of origin [2, 4]. On the other hand, it has been determined that origin can be a simple means of partitioning variation in germplasm collections. There is more relatedness between entries from a given country than between countries, even when they are neighboring countries [17].

It is important to consider the practical significance of grouping the populations into different clusters and estimating the genetic distance between them, which represents an index of genetic diversity among clusters [2]. It may be useful to produce crosses between genotypes belonging to the clusters separated by large estimated distances [2]. Success might therefore be expected through making crosses between the Tunisian natural populations in cluster 2 and the Amairia population or Algerian population (ALO56) in cluster 3 .
However, in selecting parental material, important characteristics such as pest and disease resistance, quality of produce, stability of performance and cross-compatibility should also be considered $[1,2]$. It seems that the combined effects of genetic drift and selection could have more influence on genetic diversity than geographical distance [2].

Traits discriminating the 3 groups obtained in this study can be identified via an F test (Tab. VII). The results reflect a certain "gigantism" for morphological traits suitable for agronomic purposes: large leaflets and erect habit in group 3. It has been shown that alien plants of Lotus corniculatus L. could be characterized by such vegetative characters [3].

In conclusion, the multivariate approach allowed a detailed characterization of populations of $H$. coronarium in terms of traits of agronomic interest. Valuable material, potentially useful in future breeding programs, has been identified such as the 
Algerian population (AL056) characterized by its erect growth habit and the Tunisian population (Maktar) which produces more inflorescences and prostrate axes. These populations may be crossed to combine desirable attributes, including resistance to Oïdium, thereby providing an advantage over Italian cultivars.

\section{References}

[1] Ariyo O.J., Multivariate analysis and the choice of parents for hybridization in Okra (Abelmoschus esculentus L. Moench), Theor. Appl. Genet. 74 (1987) 361-363.

[2] Bhatt G.M., Multivariate analysis approach to selection of parents for hybridization aiming at yield improvement in self-pollinated crops, Aust. J. Agric. Res. 21(1970)1-7.

[3] Bonnemaison F., Jones D.A., Variation in alien Lotus corniculatus L.1. Morphological differences between alien and native British plants, Heredity 56 (1986)129-138.

[4] Cheda H.R., Fatokun C.A, Numerical analysis of variation patterns in Okra (Abelmoschus esculentus L. Moench), Bot. Gaz. 143 (1982) 253-261.

[5] Chriki A., Combes D., Marrakchi M., Étude de la compétition pollinique chez le Sulla (Hedysarum coronarium L.), Agronomie 4 (1984)155-159.

[6] Dowdy S., Wearden S., Statistics for Research, 2nd ed., John Wiley and Sons, NY, 1991.

[7] Elle E., The quantitative genetics of sex allocation in the andromonoecious perennial, Solanum carolinense (L.), Heredity 80 (1998) 481-488

[8] Falconer D.S., Introduction to Quantitative Genetics, 3rd ed., Longman Scientific and Technical, New York, 1989.

[9] Figier J., Étude de la variabilité et du déterminisme de la morphologie de Hedysarum coronarium L. en Tunisie. Implications concernant l'amélioration de cette espèce fourragère dans ce pays, thèse doctorat d'État, Université Paris Sud, 1982.

[10] Garnock-Jones P.J., Change of adaptations from entomophily to autogamy in Parahebe linifolia (Scrophulariaceae), Plant Syst. Ecol. 137 (1981) 195-201.

[11] Houle D., Comparing evolvability and variability of quantitative traits, Genetics 130 (1992)195-204.
[12] Humphreys M.O., Assessment of perennial ryegrass (Lolium perenne L.) for breeding. Il. Components of winter hardiness, Euphytica 41 (1989) 99-106.

[13] Humphreys M.O., A genetic approach to multivariate differentiation of perennial ryegrass (Lolium perenne L.) populations, Heredity 66 (1991) 437-443.

[14] Mazer S.J., Delesalle V.A. Floral trait variation in Spergularia marina (Caryophyllaceae): ontogenetic, maternal family, and population effects, Heredity 77 (1996) 269-286.

[15] Mitchell R.J., Shaw R.G., Heritability of floral traits for the perennial wild flower Penstemon centranthifolius (Scrophylariaceae): clones and crosses, Heredity 71 (1993) 185-192.

[16] Mitchell-Olds T., Bergelson J., Statistical genetics of an annual plant, Impatiens capensis. I. Genetic basis of quantitative variation, Genetics 124 (1990) 407-415.

[17] Peeters J.P., Martinelli J.A., Hierarchical cluster analysis as a tool to manage variation in germplasm collections, Appl. Genet. 78 (1989) 42-48.

[18] Rao G.V.S., Paroda R.S., Factor analysis in clusterbean (Cyamopsis tetragonoloba L. Taub), Theor. Appl. Genet. 62 (1982) 273-276.

[19] Roff D.A., Bradford M.J., The evolution of shape in the wing dimorphic cricket, Allonemobius socius, Heredity 80 (1998) 446-455.

[20] Tomassone R., Dervin C., Masson J.P., Biométrie, Masson, Paris, 1993.

[21] Trifi F.N, Chatti W.S, Marrakchi M., Pernes J., Analyse de la variabilité morphologique et enzymatique des formes cultivées et spontanées d'Hedysarum coronarium L. en Tunisie, Agronomie 9 (1989) 591-598.

[22] Veronesi F., Falcinelli M., Evaluation of an Italian germplasm collection of Festuca arundinacea Schreb. through a multivariate analysis, Euphytica 38 (1988) 211-220.

[23] Westcott B., Some methods of analysing genotype-environment interaction, Heredity 56 (1986) 243-253.

[24] Wilson J.P., Burton G.W., Bondari K., Inheritance of height and maturity in crosses between pearl millet landraces and inbred tift $85 \mathrm{DB}$, Theor. Appl. Genet. 80 (1990) 712-718.

[25] Wolff K., Van Delden W., Genetic analysis of ecological relevant morphological variability in Plantago lanceolata L. I. Population characteristics, Heredity 58 (1987) 183-192. 